\title{
Preciso estudar para ser alguém: Memória e representações sociais da educação escolar
}

\author{
Luciene Alves Miguez Naiff \\ Universidade Salgado de Oliveira, Rio de Janeiro-RJ, Brasil \\ Celso Pereira de Sá \\ Universidade do Estado do Rio de Janeiro, Rio de Janeiro-RJ, Brasil \\ Denis Giovanni Monteiro Naiff \\ Universidade Federal Rural do Rio de Janeiro, Rio de Janeiro-RJ, Brasil
}

\begin{abstract}
Resumo: As teorias que tratam da memória social e das representações sociais entendem essas modalidades de manifestação mental como construídas e compartilhadas socialmente pelos grupos de vivências semelhantes. O objetivo deste artigo é discutir a escola e seu papel de agente de inclusão ou exclusão nas memórias de vida apresentadas. Foram entrevistadas 15 mães e 15 filhas sobre suas vidas no passado, presente e futuro. Constatamos que a instituição escolar e o ato de estudar, de uma maneira geral, representam aspectos positivos vividos no passado e se projetam nos discursos sobre o futuro como possibilidades de mudança de vida. As práticas sociais, por outro lado, expõem rotinas que não incluem a escola. Podemos inferir que isso ocorre devido ao cotidiano de vulnerabilidade a que estão submetidas as entrevistadas por gerações e a uma provável inadequação da proposta pedagógica da escola pública brasileira no que tange ao combate da evasão escolar.
\end{abstract}

Palavras-chave: Memória social. Educação. Exclusão social.

\section{I need to study to be somebody: Social memories and representations regarding formal education}

\begin{abstract}
Different theories on social memory and representation perceive these modes of manifestation as socially constructed and collectively shared. The main objective of this article is to discuss the role of the school on the memory of adults and their children. Data were collected through interviews with 15 mothers and their respective daughters on their perceptions regarding the past, present, and future. The interviews showed that, in general, the school is represented by its positive aspects and is seen as an important tool to expand life options. On the other hand, social practices incorporate aspects of everyday life that do not include the school. These differences may be explained by the interviewees' socio-economic vulnerability, and also to inadequate pedagogical practices found in the Brazilian public school system regarding its policies aimed to avoid school dropouts.
\end{abstract}

Keywords: Social memory. Education. Social exclusion.

\section{Necesito estudiar para ser alguien: Memoria y representaciones sociales acerca de la educación escolar}

Resumen: Las teorías que tratan de la memoria social y de las representaciones sociales relacionan esas modalidades de manifestación psíquica como construidas y compartidas socialmente por los grupos de vivencias semejantes. El objetivo de este artículo es discutir la escuela y su papel de agente de inclusión o exclusión en las memorias de vida presentadas. Fueron entrevistadas 15 madres y 15 hijas acerca de sus vidas en el pasado, presente y futuro. Constatamos que la institución escolar y la acción de estudiar, de manera general, representan aspectos positivos vividos en el pasado y si proyectan en los discursos acerca del futuro como posibilidades de mudanzas en la vida. Las prácticas sociales, por otro lado, exponen rutinas que no incluyen la escuela. Podemos inferir que eso ocurre debido al cotidiano de vulnerabilidades a que están sometidas las entrevistas por generaciones y a una probable inadecuación de la propuesta pedagógica de la escuela pública brasileña en lo que se refiere al combate a la evasión escolar

Palabras clave: Memoria social. Educación. Exclusión social. 


\section{Introdução}

Não obstante a educação no Brasil remontar aos tempos dos jesuítas, suas finalidades e alcances ficaram por muito tempo restritos a determinadas parcelas sociais (Saviani, 2006), podemos, inclusive, entender como um fenômeno relativamente novo na história da educação brasileira o desenvolvimento de uma escola pública tal qual conhecemos hoje (Vieiras $\&$ Farias, 2007). Conquistas recentes como a consagração da educação escolar enquanto direito subjetivo proposto na Constituição de 1988 e a Lei $\mathrm{n}^{\circ}$. 8.069/90, também conhecida como Estatuto da Criança e do Adolescente (Brasil, 2005), que estabelece a educação como um dos direitos básicos das crianças e adolescentes no Brasil, vêm atingindo em cheio as representações sociais sobre a escola e a sua função social.

Embora o ensino básico das escolas públicas brasileiras tenha produzido mudanças positivas nas últimas três décadas, os níveis de discrepância entre idade e série, evasão escolar e repetência ainda são altos se comparados às estatísticas de países com renda per capita similares (Instituto Nacional de Estudos e Pesquisas Educacionais Anísio Teixeira [INEP], 2006). Segundo Gilly (2001), os mais pobres vêem sistematicamente suas trajetórias escolares fracassadas por um presente pouco receptivo e por um futuro profissional sem grandes expectativas. Nesse sentido, a escola é o espaço da convivência de uma multiplicidade de significações sociais produzidas pelos atores que direta ou indiretamente se envolvem em seu sistema, fazendo da área educacional, segundo Gilly (2001, p. 322):

um campo privilegiado para se observar como as representações sociais se constroem, evoluem e se transformam no interior de grupos sociais, e para elucidar o papel dessas construções nas relações desses grupos com o objeto de sua representação.

Assim, entendemos a escola não apenas como um espaço de aprendizagem, mas também de socialização, formação de atitudes e de representações sociais (Alves-Mazzotti, 2005), cujas relações sociais construídas nesse ambiente podem ser importantes facilitadoras do processo de ensinoaprendizagem, como sugere Freire (1992).

Atualmente, muito se discute sobre a provável relação existente entre os fenômenos da exclusão social e os da baixa escolaridade. Não se trata de, nesta postulação, focar apenas a relação direta e inequívoca da necessidade cada vez maior de escolaridade para inserção no mercado de trabalho. Os aspectos psicossociais e identitários são extremamente relevantes para se pensar o que afeta a vida escolar dos grupos sociais mais vulneráveis economicamente (Naiff, 2005). A esse respeito, veremos, no presente artigo, as inter-relações entre pobreza e educação, os referenciais teóricos das representações sociais e da memória social, e por fim, a pesquisa empírica que busca contribuir, do ponto de vista da psicologia social, para um melhor entendimento desse campo.

\section{Educação e pobreza no Brasil}

Nos últimos anos temos assistido a mudanças muito rápidas e significativas do panorama mundial no campo político, econômico e social. Na mesma linha de pensamento, Gadotti (1998) acredita que a escola atravessa uma crise paradigmática que implica na busca incessante de estratégias reflexivas sobre seu papel social. O que Patto (1999) chamou do "Mito do fracasso escolar" produzido por uma excessiva atribuição de causalidade pessoal a fenômenos como capacidade de aprendizagem e evasão escolar, traz na atualidade um convite a reflexões menos simplistas que busquem entender o aluno enquanto sujeito sóciohistórico, inserido em diversos contextos, com formas diferenciadas de ver o mundo. Principalmente quando falamos de um alunado empobrecido que sofre os preconceitos e desenvolve, muitas vezes, uma relação de afastamento com o processo formal de educação. Certamente, muitos dos aspectos vivenciais relacionados à escolaridade ou a sua ausência, trazem significados que podem afetar o futuro desse indivíduo, sua auto percepção e a de seu grupo social, como bem salienta Esteban (2001, p. 106):

Tal compreensão indica um aspecto significativo para a discussão do baixo rendimento escolar nas classes populares. Se o castigo 
Naiff,L.A.M., Sá, C.P. \& Naiff, D.G.M. (2008). Memória e representações sociais da educação 127

passa a efetivar-se através da suspensão dos direitos - o que na escola se traduz em notas baixas, repetência e impedimento (formal ou não) de prosseguimento da vida escolar - é bastante compreensível que tenha um poder muito pequeno para impor a disciplina aos estudantes pertencentes a essas camadas sociais. Eles já têm uma vida cotidiana de negação de direitos, a privação de direitos no dia a dia escolar ou a privação de direitos futuros como conseqüência da não escolarização, não servem como ameaças suficientes e não exercem pressão bastante para moldálos às exigências escolares. A vida cotidiana constrói seu sentimento de incapacidade, o fracasso escolar é apenas um fracasso a mais.

O fenômeno da pobreza, em suas diversas manifestações, produz indivíduos que, para sobreviverem, devem se adaptar a seus contornos e com isso gerar respostas às demandas da vida social baseadas em sua lógica de vida. Falar de pobreza no Brasil nos remete a um amplo e multifacetado terreno. Vivemos nos dias de hoje com o que Martins (1997, p.14) chama da "nova desigualdade", que separa economicamente, mas aproxima ideologicamente, ampliando o sentimento de desigualdade. Associado a isso, a dificuldade de inserção em um mercado de trabalho cada vez mais competitivo e especializado gera aqueles que vêm sendo chamados de "eternamente pobres", gerações que nunca vão chegar a entrar no trabalho formal, desenvolvendo atividades de geração de renda instáveis de baixo retorno financeiro ou vivendo da assistência social instituída (Singer, 1998; Góes de Oliveira, 1997; Véras, 1999).

A pobreza gera procura por alternativas objetivas de sobrevivência, mas gera também um estado, uma alteridade que provoca estranhamentos entre os grupos sociais, comprometendo a vivência da cidadania e do sentimento de humanidade que deveria unir os indivíduos (Buarque, 1993; Paugam, 1999). É nesse contexto mais amplo que sobrevivem as participantes da presente pesquisa, vivenciando os meandros subjetivos e objetivos de ser pobre em meio às modernizações do mundo atual.
A vinculação mais objetiva entre escolaridade e renda vai mostrar que existe uma relação diretamente proporcional entre anos de estudo e melhoria nas condições de vida da população (Instituto Brasileiro de Geografia e Estatística [IBGE], 2000). Isso aponta para o fato de que estar na escola, aprendendo, constitui-se em uma possibilidade de mudança nas perspectivas de inserção no mercado de trabalho e conseqüente maiores chances de geração de renda.

Outro aspecto que chama atenção é a comparação entre o nível de escolaridade de quem reside nas comunidades de baixa renda conhecidas como favelas e de quem reside nas outras áreas do Rio de JaneiroRJ. Na zona sul (área residencial nobre da cidade), por exemplo, 33,7\% dos moradores de favelas não tinham instrução nenhuma e $40 \%$ estudaram com aprovação até quatro anos; enquanto que entre a população não residente em favelas apenas $7,2 \%$ não tinham instrução, e 38,9\% possuíam mais de 12 anos de estudo. Os dados são semelhantes na zona norte, na qual 35,6\% dos moradores de favelas não têm nenhuma instrução e 39,9\% estudaram com aprovação até quatro anos, enquanto que entre os moradores em geral 39,5\% tiveram mais de 12 anos de estudo formal (Prefeitura do Rio de Janeiro, 2001).

Do que foi exposto acima, percebemos como estatisticamente os dados mostram uma inter-relação entre pobreza e baixa escolaridade. Mas, se temos atualmente uma escola universalizada, obrigatória e gratuita, e se os estudos mais objetivos sobre pobreza mostram que a escolaridade é um fator importante de mudança na situação sócio-econômica, o que faz com muitos vivam à margem do acesso a educação?

O universo escolar tradicionalmente é um grande foco de pesquisas nas áreas da educação e da psicologia, devendo-se notar o aumento dos estudos psicossociais em busca do entendimento de fenômenos a ele ligados (Gilly, 2001; Alves-Mazzotti, 2005). É compondo esse caminho que propomos entender o fenômeno da educação através do pensamento social e da memória de um grupo de mulheres que vivencia a exclusão social e suas mazelas por mais de uma geração. $\mathrm{Na}$ perspectiva psicossocial aqui proposta, o indivíduo é entendido 
como essencialmente um ator social, isto é, produto e produtor de sua realidade. Inserida neste contexto, podemos entender que a escola apresenta tanto conteúdos sedimentados pelo controle social como também elementos produzidos e reproduzidos no ambiente em que o sujeito vivência e compartilha (Sá, Möller \& Medeiros, 1990).

\section{Memória social e aspectos psicossociais}

Na psicologia, durante décadas, a memória humana foi extensamente estudada como se fosse apenas um tema individual. Há algum tempo, tem-se observado nas ciências sociais um retorno do interesse pelo estudo das dimensões sociais e culturais presentes na memória humana, primeiramente no âmbito da sociologia e da história e mais recentemente na psicologia social. Segundo Garzón (1998), “o contexto social da memória vem sendo reivindicado pelos psicólogos há pouco mais de uma década" (p.17). Neste sentido, Páez, Basabe e Gonzáles (1998, p. 176) afirmam que:

Desde distintas tradições psicossociológicas se postula que existem processos psicológicos que transcendem o indivíduo, mesmo quando se manifestam através dos indivíduos. É dizer, existem processos que se bem se apóiam em atividades individuais e se atualizam nelas, têm uma autonomia e eficácia própria. Em nosso caso, nos referimos a estes fenômenos como processos coletivos de memória.

O conceito de memória social, da forma como vem sendo trabalhado na atualidade, tem basicamente suas origens nas teorizações seminais, na primeira metade do século XX, do sociólogo francês Maurice Halbwachs e do psicólogo britânico Frederick C. Barttlett (Bosi, 1994, 2003; Namer, 1987; Sá, 2005; Sá, 2007). Descendente de uma tradição francesa de psicologia coletiva (ou sociologia psicológica, como se dizia à época), Halbwachs realizou uma verdadeira síntese dos pontos de vista opostos de Durkheim e de Tarde, famoso professor do Collège de France que criticava o antipsicologismo de Durkheim, integrando o social na psicologia individual (Mucchieli \& Pluet-Despatin, 2001).
Enfatizando a impossibilidade de se pensar a memória enquanto uma estrutura mental individual, Halbwachs $(1925 / 1994,2006)$ afirmava que os indivíduos se lembram dentro de um grupo social, usam referências determinadas pela sociedade, têm a tendência a utilizar as memórias de outras pessoas para reforçar suas próprias, baseando-se em uma estrutura de linguagem e comunicação na construção de suas lembranças. Isto não quer dizer que, por serem todas as memórias coletivas, as pessoas lembrem sempre a mesma coisa. Na verdade, segundo Halbwachs, as lembranças individuais não passariam de pontos de vistas de uma situação vivida coletivamente. Vários desses pontos de vista, vividos em grupos diferentes, gerariam o aspecto individual da memória (Viaud, 2002).

As principais idéias associadas à noção de memória coletiva presentes em Halbwachs poderiam ser resumidas da seguinte forma: em primeiro lugar, toda a memória é social pelos seus conteúdos. Sempre recordamos um mundo no qual existe a presença de outras pessoas. A memória de um passado é intersubjetiva, compartilhada e recordada conjuntamente, ou seja, toda memória individual em sua gênese é social, pois para lembrar de seu passado, todo indivíduo ancora-se nas reminiscências e nas figuras dos outros (Namer, 1987); em segundo lugar, a memória é social porque está apoiada nos "quadros sociais de referência" (les cadres sociaux), como os rituais, as cerimônias, os eventos sociais, entre outros. Até o tempo é visto aqui, como "um quadro social que permite aos indivíduos e aos grupos sociais constituírem sua memória" (Viaud, 2002, p.24); e em terceiro lugar, a memória é social ou intersubjetiva porque se baseia, principalmente, na linguagem e na comunicação lingüística externa e interna existente nos grupos.

Um outro modelo de entendimento dos processos psicossociais envolvidos na atividade mnemônica humana foi desenvolvido pelo psicólogo social britânico Frederick C. Bartlett, fortemente influenciado pela escola inglesa de antropologia e que comungava com Halbwachs das idéias sobre os aspectos construtivos da memória humana, expondoas através de sua obra seminal Remembering: a study in experimental and social psychology 
(Bartlett, 1932/1995). Bartlett estudou o funcionamento individual da memória humana introduzindo a noção de esquema, enquanto estruturação de uma "memória de fatos". Nesse modelo, não existiriam memórias específicas guardadas na mente ou no cérebro, mas apenas traços deixados pela experiência (esquemas) que se transformariam toda vez que fossem ativados para produzir uma atividade concreta no curso de uma ação em marcha. Desta forma, as memórias não seriam fixas, mas sim recriações do passado que produziriam em nós um sentido de continuidade, um sentimento de ser uma entidade com passado e com futuro (Rosa, Bellelli \& Bakhurst, 2000). Logo, o processo de recordar algo implicaria em ter acesso a informações disponíveis como resultado das tentativas de reconstrução do passado no presente, através de algum propósito social e/ou psicológico particular a partir da lembrança coletiva de acontecimentos pessoais e históricos.

Uma das características do enfoque de Bartlett era sua ênfase no valor afetivo, emocional que as percepções e imagens produzem no indivíduo (Rosa e cols., 2000). Estes efeitos teriam uma importância de primeira ordem nas recordações e também nos significados atribuídos às representações dos indivíduos, sejam estas narrações verbais ou tenham uma natureza imagética, sejam frutos da percepção atual ou do resultado da lembrança. Para Bartlett, as lembranças sempre teriam elementos emocionais associados, de maneira que reunir objetos mediadores no processo de recordação teria freqüentemente como objetivo principal reviver um determinado sentimento (Van der Veer, 2001).

A literatura tem apontado para as similitudes presentes nos campos epistemológicos da memória e das representações sociais, entendendo que o diálogo auxilia na aproximação das dimensões psicossociais envolvidas na vivência dos fenômenos socialmente produzidos e partilhados. Explorando as relações existentes entre memória e representações sociais, Jedlowski (1997) conceitua as memórias sociais como "representações sociais referentes ao passado: a imagem do passado é produzida, conservada, elaborada e transmitida por um grupo através das interações dos seus membros" (p.24).
Na mesma direção, Emelyanova (2002) defende que "a memória social pode ser concebida tanto como um processo de atualização das representações sociais do passado, quanto como um processo de elaboração, de transformação ou de esquecimento destas representações sociais" (p.140). Essas representações do passado, segundo Jedlowski (2001), são destinadas a dar legitimidade às crenças da sociedade e para inspirar seus projetos, legitimando assim as elites que os produzem. Quanto maior é a complexidade de uma sociedade, maior é o numero das elites competindo para dominá-la; logo, mais o passado torna-se o assunto de estratégias visando impor as representações que concordam com os interesses dominantes. Na mesma linha de pensamento, a abordagem estrutural das representações sociais postula que o sistema central de uma representação tem, dentre outras características, a de ser intrinsecamente ligado à memória social e à história do grupo que mantém tal representação (Abric, 2003).

Desta forma, como concluem De Rosa e Mormino (2000), tanto a memória social quanto as representações sociais:

permitem a interpretação do presente a partir de quadros de referência ligados ao passado, mas também ancorados no presente.... A elaboração e a perpetuação das visões de mundo dependem simultaneamente do trabalho da memória e da atividade cognitiva (p.124).

A memória se alimenta de lembranças do passado, mas se apresenta configurada pelo eu presente e tudo que o influencia, sejam aspectos culturais, representações sociais, preconceitos ou estereótipos (Roussiau \& Bonardi, 2002).

A pesquisa realizada no presente estudo procurou chegar a uma memória oral das participantes, que ao mesmo tempo é autobiográfica, porque diz respeito à vida privada de cada uma, e social porque se reporta às crenças, representações sociais, discursos e vivências comuns a todas elas. Vale nesse sentido citar Sá (2005) que em seu esforço de construção de uma proposta de classificação das variadas instâncias que hoje se estuda sob o rótulo 
de memória social, a saber: memórias pessoais, comuns, coletivas, históricas, práticas e públicas; encontrou em comum:

seu caráter construtivo ou reconstrutivo, sua constituição simultaneamente social e individual, sua dependência da comunicação e interação social, sua imbricação com o pensamento social e sua dinâmica afetiva (p. 83).

As representações sociais e as memórias de duas gerações de mulheres produzem sentidos para o papel da escola e da educação formal em suas vidas, tornando-se, em última análise, algo que lhes confere um saber sobre o mundo a sua volta e uma identidade social.

\section{Objetivo}

Os objetivos deste estudo foram identificar e comparar, nas reminiscências de mães e filhas, os conteúdos psicossociais articulados em torno dos fenômenos escola e educação formal.

\section{Método}

\section{Sujeitos}

Foram entrevistadas 30 mulheres que vivem na cidade do Rio de Janeiro-RJ, divididas em dois grupos de mães e filhas: (a) um grupo principal de 15 mulheres com idades entre 37 e 57 anos, moradoras de aglomerados subnormais conhecidos como favelas ou invasões ${ }^{1}$; (b) um grupo secundário de 15 filhas das mulheres do grupo principal, com idades a partir dos 17 anos. As mulheres que compõem o grupo das filhas também são mães. Em sua pesquisa sobre o universo feminino, Rocha-Coutinho (1994) salienta a importância de poder resgatar as falas de mães e filhas submetidas à influência de discursos diferentes e muitas vezes contraditórios.

Do grupo principal, composto pelas mães, onze não trabalhavam, duas exerciam atividades formais de geração de renda e duas eram aposentadas pela Previdência Social. Em relação as suas escolaridades, onze mães estudaram até o $6^{\circ}$ ano (antiga $5^{\mathrm{a}}$ série ou $1^{\circ}$ ano do segundo segmento do ensino fundamental) e quatro mães estudaram acima do $6^{\circ}$ ano.
Do grupo secundário, composto pelas filhas, 14 não trabalhavam e apenas uma exercia atividade formal de geração de renda. Dentre as que relatavam não trabalharem, seis eram atendidas por programas sociais não governamentais e três exerciam atividades de geração de renda informais ("catação de latinhas", venda de doces e balas em sinais de trânsito). No que tange a escolaridade, 13 filhas conseguiram estudar do $6^{\circ}$ ano em diante e somente duas estudaram até o $6^{\circ}$ ano.

Enquanto as mães tiveram, em sua maioria, até cinco anos de estudos na infância e adolescência, as filhas tem um número superior a sete anos de estudo. Esses dados apontam para uma tendência, comprovada pelos últimos resultados censitários (IBGE, 2000; INEP, 2006), de revalorização do estudo formal, além da própria ampliação do acesso à escola pública ocorrido nas últimas décadas. Isso não diminui, contudo, as dificuldades que a população de baixa renda encontra para se manter na escola por um período mais longo, principalmente pela necessidade imediata de geração de renda (Naiff \& Naiff, 2007). Esse dado é corroborado na presente pesquisa pelo fato de que apenas uma componente do grupo das filhas e uma componente do grupo das mães estavam estudando na ocasião da coleta de dados.

$\mathrm{O}$ recorte de idade do grupo principal de colaboradoras (mães) seguiu a orientação de Conway (1990, 1991, 1995, 1998) que argumenta ser a partir dos 35 anos que as lembranças da etapa da vida entre doze e vinte e um anos - isto é, o "boom" de reminiscências ou idade crítica - ficam mais nítidas, pois seria nesta fase anterior, entre a adolescência e os primeiros anos da vida adulta, que ocorreria a formação da identidade geracional. Além disso, a partir de 35 anos, o indivíduo seria capaz de desenvolver uma narrativa estruturada sobre a sua vida, organizando sua memória em torno de um "eu"

\footnotetext{
${ }^{1} \mathrm{O}$ IBGE define aglomerados subnormais como grupos de mais de cinqüenta unidades habitacionais dispostas de modo desordenado e denso sobre solo que pertence a terceiros e carente de serviços públicos essenciais. Opõem-se aos setores especiais ou normais que se define como cidade formal (IBGE, 2000).
} 
Naiff,L.A.M., Sá, C.P. \& Naiff, D.G.M. (2008). Memória e representações sociais da educação 131

mais estável. O grupo secundário das filhas, a maioria ainda vivenciando a idade crítica da formação identitária, teria nas lembranças aspectos mais relacionado a um passado recente que estaria constantemente sendo "manuseado" para compor o que futuramente será sua identidade geracional.

\section{Coleta de dados e análise dos dados}

Seguindo a orientação proposta por Joutard (2000), a denominação "campo de estudo de uso de fontes orais" define melhor nossa proposta de coleta de dados. Essa denominação permite pensar a oralidade como um recurso metodológico para análise do material mnemônico em si através da forma como esse material é resgatado e relembrado pelo sujeito.

Resgatar as memórias sociais apoiadas em quadros de referências do grupo só é possível a partir da análise das narrativas autobiográficas de seus membros, como afirma Cipriani (1988, p. 118): “aquilo que mais ressalta na coleta de uma série de histórias de vida é a possibilidade de ver desenvolver-se as diversas biografias individuais sobre um terreno largamente partilhado a nível social". É por meio do relato autobiográfico que identificaremos a influência do tempo presente e dos grupos sociais oferecendo, como Namer (1987) propõe, um meio para se atingirem tanto os "quadros de referência social", na memória individual do sujeito, quanto as manifestações de uma memória coletiva e social.

As entrevistas foram realizadas com as mães e filhas em seu ambiente domiciliar ou em espaços cedidos por organizações não governamentais. Foram selecionadas díades que viviam com renda familiar per capita inferior a meio salário mínimo, valor considerado basal para a inclusão nos programas nacionais de renda mínima brasileiros.

As falas foram gravadas, transcritas e submetidas a um processo de análise de conteúdo. O texto transcrito foi submetido ao processo de categorização que fez emergir as palavras ou sentenças que simbolizavam a força expressiva dos acontecimentos e opiniões mais importantes (Bardin, 1992). Segundo Nascimento e Menandro (2006), o principal objetivo da análise de conteúdo como técnica de apropriação de sentidos se refere a identificação de regularidades, que buscam: "identificar a pluralidade temática presente num conjunto de textos, ao mesmo tempo em que pondera a freqüiência desses temas dentro de um mesmo conjunto" (p.79).

Os sujeitos/colaboradores foram tomados como "unidades de enumeração", de modo que não importavam quantas "unidades de registro" (falas) cada um deles tivesse em uma dada categoria, mas apenas a presença ou ausência daquele tipo de rememoração (categoria).

\section{Resultados e Discussão}

Os relatos em que apareciam aspectos psicossociais e mnemônicos em relação à escola e a educação formal foram agrupados em quatro grandes categorias, a saber: (1) Lembranças da escola; (2) Lembranças do trabalho na infância e adolescência; (3) Possibilidades de mudança de vida; e (4) Arrependimentos. Em cada uma dessas categoriais gerais, os elementos (palavras ou frases) foram agrupados em subcategorias representativas do conteúdo apresentado, conforme exposto nas Tabelas 1, 2, 3 e 4 .

Tabela 1

Distribuição das subcategorias das lembranças da escola $(n=30)$

LEMBRANÇAS DA MÄES FILHAS
ESCOLA

\begin{tabular}{lll}
\hline Lugar bom de aprender & 5 & 7 \\
Não gostava & 3 & 4 \\
Não tem lembranças & 7 & 4 \\
\hline
\end{tabular}

A Tabela 1 apresenta a escola gerando lembranças positivas como espaço de brincadeiras, de aprendizado, e principalmente de um projeto de futuro para o grupo das filhas: "Eu estudei e gostava porque a escola ia me dar oportunidade de ter uma vida melhor diante da sociedade" (Andréa, 32 anos, grupo das filhas, mãe de duas meninas, uma de dez anos e outra de seis meses).

No grupo das mães, praticamente a metade relatou possuir pouca ou nenhuma lembrança 
vinculada à escola ou à educação formal, como lembra Carina: "Eu adoro até hoje, sempre gostei, mas minha mãe não dava tempo, todo tempo que eu tinha pra estudar, minha mãe botava pra eu trabalhar" (Carina, 57 anos, grupo das mães, mãe de quatro filhos, duas mulheres de 36 e 17 anos e dois homens, um de 19 anos e outro assassinado aos 18 anos).

\section{Tabela 2}

Distribuição da freqüência de lembranças em relação ao trabalho infantil nos grupos de mães e filhas $(n=30)$

\begin{tabular}{lcc}
\hline $\begin{array}{c}\text { TRABALHO } \\
\text { INFANTIL }\end{array}$ & MÄES & FILHAS \\
\hline Sim & 10 & 6 \\
Não & 5 & 9 \\
\hline
\end{tabular}

O trabalho infantil se faz mais presente na memória do grupo das mães (Tabela 2). Percebemos, quando analisamos as lembranças relatadas, uma preocupação de poupar as filhas do trabalho na infância para diferir de sua própria realidade. $\mathrm{O}$ trabalho na infância marcou bastante a trajetória de vida das mulheres do grupo das mães. A miséria, o abandono dos pais e a falta de leis que protegessem a criança trabalhadora reforçavam esse quadro. $\mathrm{O}$ trabalho mais comum do grupo das mães consistiu no exercício da profissão de doméstica, introduzido normalmente por algum familiar: "Eu ia pra ajudar minha mãe no serviço dela, foi assim que eu comecei" (Mônica, 38 anos, grupo das mães, mãe de cinco filhos: três meninos de treze, dez e sete anos e duas meninas de 17 e 16 anos). No grupo das filhas observamos a atividade relacionada à venda de doces, balas, dentre outras guloseimas, nas ruas, como principal prática de geração de renda na infância e nem sempre considerada, tanto pelas mães quanto pelas filhas, como trabalho: "Eu vendia doce, quando não vendia eu pedia, mas fora isso, não trabalhei não" (Sarita, 17 anos, grupo das filhas, mãe de um menino de seis meses).

Os resultados apontam para uma mudança quanto à percepção sobre o trabalho infantil entre as gerações estudadas. Alguns fatores podem ter influenciado esses dados: a valorização da escola formal como espaço de aprendizado e complemento na socialização das crianças e o Estatuto da Criança e do Adolescente proibindo a exploração do trabalho infantil e criminalizando quem faz uso dessa prática; outrossim, o aparecimento de incentivos financeiros para as famílias com filhos na escola e fora do trabalho infantil também vêm reforçando as mudanças de práticas nesse sentido, reflexo identificado principalmente a partir da geração das filhas e de seus filhos (Senna, Burlandy, Monnerat, Schottz \& Magalhães, 2007). Entretanto, o trabalho ainda concorre com a escola na dedicação de tempo dado pelas entrevistadas do grupo das filhas. Estas, apesar de terem tido mais anos de estudo, desistiram da escola ainda precocemente, obtendo um nível de escolaridade que permite a inclusão no mesmo mercado de trabalho que o das mães, quais sejam: serviços domésticos, babás, ambulantes, catadoras, dentre outros que exigem pouco ou nenhum nível instrucional.

\section{Tabela 3}

Distribuição das subcategorias das possibilidades de mudança na situação de vida atual $(n=30)$

\begin{tabular}{lcc}
\hline $\begin{array}{l}\text { POSSIBILIDADES DE } \\
\text { MUDANÇA DE VIDA }\end{array}$ & MÃES & FILHAS \\
\hline Força de vontade & 10 & 8 \\
Estudo & 2 & 3 \\
Auxílio Externo & 1 & 3 \\
Nenhuma & 2 & 1 \\
\hline
\end{tabular}

A sociedade funciona em um suposto ideal de igualdade, sancionando leis e criando papéis com base na percepção de que todos podem estar onde quiserem na teia social, bastando para isso seguir alguns princípios gerais. Mesmo sendo o dia-a-dia das famílias empobrecidas em muitos aspectos diferente deste ideário, encontramos nas categorias apresentadas na Tabela 3 representações sociais das possibilidades de mudança relacionadas à decisão individual de transformar a situação de vida, como exemplificado na fala desta mãe: "Podem mudar de vida desde o momento que elas queiram mudar e estiverem cansadas de viver nessa vida de um dia ter o que comer outro dia não" (Emília, 50 anos, grupo das mães, mãe de cinco filhos, três mulheres de 33, 
Naiff,L.A.M., Sá, C.P. \& Naiff, D.G.M. (2008). Memória e representações sociais da educação 133

27 e 18 anos e dois rapazes, um já falecido e outro de 16 anos); ou desta filha: "Ser otimista. Acho que você tem que colocar na cabeça, eu quero ter, eu vou ter" (Patrícia, 17 anos, grupo das filhas, mãe de uma menina de oito meses). A categoria estudo aparece mais freqüente que a categoria esperança em auxílio externo, mas muito timidamente como possibilidade de mudança de vida isoladamente, em relação à força de vontade que parece ser por si só um dispositivo de mudança nas representações das entrevistadas, tanto as mães quanto as filhas.

\section{Tabela 4}

Distribuição das subcategorias dos arrependimentos (o que gostariam de ter feito na vida) $(n=30)$.

\section{GOSTARIAM DE TER MÃES FILHAS} FEITO

\begin{tabular}{lll}
\hline Estudado & 7 & 5 \\
Mudança de local de moradia & 4 & 3 \\
Trabalho & 2 & 5 \\
Não ter filhos & 2 & 2 \\
\hline
\end{tabular}

A escola formal ganha força no grupo das mães quando o assunto é a situação de arrependimento em relação à vida que levaram, como mostra a tabela 4 . O discurso da escola como meio legítimo de ascensão social e do trabalho formal como forma de existir na qualidade de cidadão é possivelmente a causa dos sentidos presentes nessas percepções: "Eu não pude estudar aquilo que eu gostaria e ter um bom emprego" (Carla, 53 anos, grupo das mães, mãe de dois filhos, um homem de 33 anos e uma mulher de 32 anos). No grupo das filhas, tanto estudar quanto trabalhar aparecem com o mesmo peso nas subcategorias analisadas, o que, pela própria idade das entrevistadas, aponta muito mais como um projeto de vida do que como reminiscências de um passado, ainda tão presente em suas vidas. Ressalte-se, novamente, o peso simbólico atribuído à educação e à instituição escolar como possibilidade de mobilidade social, bem exemplificado pela fala de Marinalva: "Pra mudar de vida, primeiro é estudar direitinho para nossos filhos não precisarem passar pelas coisas que passamos" (Marinalva, 30 anos, grupo das filhas, mãe de dois meninos de nove e quatro anos).

\section{Considerações finais}

Os programas compensatórios criados pelos governos municipais, estaduais e federais, além das ações da sociedade civil organizada esbarram nas dificuldades de inserção no mercado de trabalho dos estratos mais pobres em nossa sociedade, inserção esta que a literatura aponta, na modernidade, como única forma duradoura de conquista da autonomia. O que acontece são famílias, às vezes por gerações, vivendo de assistência social (Martins, 1997; Nascimento, 2000).

A percepção da importância da educação como meio de ascensão social esteve muito presente nas falas das colaboradoras, contudo a escola não faz parte das principais escolhas que elas fizeram nos últimos anos em suas vidas. Isto pode indicar uma série de variáveis que interferem na permanência dos mais pobres no ambiente escolar, dentre as quais podemos elencar algumas que aparecem freqüentemente em pesquisas sobre essas temáticas: inadequação da escola para lidar com as questões que envolvem a vivência da pobreza, necessidade de geração de renda imediata e, portanto, falta de tempo para ir à escola; gravidez na adolescência; e uma vida muito presa às necessidades do presente, sem compromisso com os ganhos futuros que a promessa da escolaridade poderia oferecer.

O propósito da presente pesquisa centrou-se no ângulo de quem vivencia a pobreza e é, portanto, autoridade para definir de que está sofrendo, do que sente falta, o que acha que está deixando de ter ou de ser. Martins (1997, p.18) nos orienta quanto a esse aspecto :

a exclusão é apenas um momento da percepção que cada um e todos podem ter daquilo que concretamente se traduz em privação: privação de emprego, privação de meios para participar do mercado de consumo, privação de bemestar, privação de direitos, privação de liberdade, privação de esperança. É isso, em termos concretos, o que vulgarmente chamamos de pobreza .

Do ponto de vista dos estudos da memória, Halbwachs propõe um modelo bi-dimensional, 
composto por uma função global e por uma função grupal. A principal característica da função global seria a nostalgia, aquele sentimento que parece caracterizar as gerações quando exercem a atividade de "olhar para trás" e achar que antes era tudo melhor, mais tranqüilo e mais fácil. É a chamada "idade de ouro", quando as famílias eram mais unidas e a vida social menos violenta (Laurens, 2002). A segunda função, a grupal, se relaciona com as necessidades e interesses atuais dos grupos. A memória social atuaria como uma reconstrução do passado, adaptando a imagem dos fatos antigos às crenças e necessidades do presente (Schwartz, 1990; Middleton \& Edwards, 1990). Ela também serviria para estabelecer a identidade grupal, apresentandose igualmente enquanto um instrumento político de reconhecimento, permitindo introduzir relações de poder entre os grupos sociais (Viaud, 2002). A isso atribuímos a visão idealizada e positivada da escola nas reminiscências, que fazia parte do conjunto de vivências que definiam a infância, e tudo que ela deveria significar, atualizada pela visão do presente. Portanto, entrevemos tanto a função global da memória no resgate do passado "bom" quanto a função grupal de que se não existe esse passado bom é por culpa da falta de força de vontade de quem o viveu, aspecto de menos valia que vem sendo incutido nos grupos mais empobrecidos por gerações.

Bassanezi (2004) discute o papel da mulher da década de 1950 e início da década de 1960 pautado pela realização no casamento e maternidade. O estudo não era a opção mais difundida, principalmente nas classes sociais menos favorecidas. Não obstante, a necessidade de geração de renda já era uma realidade para esse grupo social. Segundo Szymanski (2006) as práticas educativas familiares compõem a transmissão do que deve se perpetuar no núcleo familiar, e nesse sentido, são responsáveis também pela difusão da memória e das representações sociais. A percepção do sentido de "ser alguém" se relaciona atualmente à necessidade de pertencimento e inclusão, próprios a um modelo de cidadão presente em nossa cultura. Isso inclui adequação a esse ideário. Szymasnki (2006) encontrou nas práticas educativas familiares a preocupação das famílias, em especial das mulheres, em produzir o indivíduo social adaptado.
A análise dos relatos de vida das mulheres moradoras de favelas, participantes desta pesquisa, toma um passado marcado por privações, exclusão social e formas de ver o mundo baseado nas representações compartilhadas por seu grupo social. As práticas sociais, agravadas por diferenças socioeconômicas, denunciam especificidades grupais que, em última análise, são as referências sociais que nos apoiamos para criar nossa identidade e que vão interferir em nossa percepção do mundo e na memória de nossas vivências. Soma-se a isso os aspectos afetivos e emocinais, citados por Bartllet (1995), envolvidos na tarefa de recordação e formação do "eu" presente. Teremos diferenças na reconstrução de nosso passado de acordo com a manutenção da identidade que queremos ou de que precisamos no momento de lembrar. Portanto, ao falar de memória, é importante relacioná-la ao grupo social no qual se está trabalhando, já que ela está a serviço da identidade do grupo e portanto tende sempre a reforçar essa identidade. Segundo Meihy (1996, p. 96):

A memória social é o conjunto das manifestações de grupos que guardam visões articuladas sobre si e sobre o mundo. A base cultural de algumas comunidades explica a adesão de setores sobre princípios gerais, éticos ou políticos que amplas camadas das populações organizam.

A relação entre memória e identidade é sentida tanto no plano individual, permitindo um sentimento de continuidade, quanto no plano coletivo, favorecendo um sentimento de pertencimento aos membros do grupo (Jodelet, 1999). A relação das famílias com a escola nem sempre é tão amistosa no cotidiano quanto as lembranças possam ter mostrado no presente estudo. Sentimentos de baixa estima, ainda em consequiência da atribuição do fracasso escolar ao indivíduo, podem prejudicar a capacidade crítica que nossas entrevistadas têm do papel que a escola pública assume com a educação (Patto, 1999). Podemos visualizar esse aspecto quando associamos as Tabelas 3 e 4 . Simultaneamente enquanto atribuem à força de vontade as posibilibilidades de mudança de vida, se arrependem de não terem estudado como deveriam, ou seja, responsabilizam-se unicamente 
Naiff,L.A.M., Sá, C.P. \& Naiff, D.G.M. (2008). Memória e representações sociais da educação 135

pelas mudanças que poderiam ter ocorrido em suas vidas, principalmente via educação formal.

A escola tende, por sua vez, a incorporar a lógica da hegemonia cultural e alijar de seu espaço àqueles que não servem a essa lógica (Manacorda, 2006; Freitas, 2002; Cruz, 2006), provocando na prática cotidiana uma desistência, um sentido de desesperança daqueles que querem ir a escola, mas não conseguem ancorar de fato nessa atitude uma mudança de vida. Nesta direção, Perrenoud (2004, p. 55) alerta para uma das possíveis dimensões presentes na evasão escolar: o medo; "medo de não aprender e ser ridicularizado, humilhado, agredido". Os argumentos de Cruz (2006, p.175) nos falam desse aspecto:

Os alunos são excluídos de ser sujeitos sociais, destituídos da possibilidade de um lugar social, por não possuírem o atestado que garante sua inserção social, por não corresponderem às expectativas sociais, já que a escola e os sistemas de aprovação/reprovação via desempenho escolar validam a ocupação do lugar social.

A guisa de conclusão podemos visualizar dois aspectos que emergem dos resultados apresentados e discutidos na presente pesquisa: de um lado vemos a escola positivada e algo idealizada nas lembranças e representações das entrevistadas, em contraponto com os diversos estudos apresentados em que esse espaço social se mostra pouco sensível às questões trazidas pelos mais pobres; por outro lado, temos a vida real das duas gerações que produzem comportamentos identitários em que estudar não aparece entre as escolhas mais preeminentes. Em suma, a explicação não está somente na escola e em suas práticas, e tampouco pode-se entender toda essa complexidade olhando apenas para o sujeito e seu grupo social. Isso nos remete a necessidade de cada vez mais estabelecer diálogos entre os campos de estudo que tratam dos fenômenos psicossociais e educacionais, buscando encontrar sentidos que auxiliem a tarefa de transformar a instituição escolar e a educação formal em dimensões efetivamente inclusivas e presentes na história de vida das populações menos favorecidas economicamente em nossa sociedade.

\section{Referências}

Abric, J.-C. (2003). La recherche du noyau central et de la zone muette des représentations sociales. In J.-C. Abric (Org.), Méthodes d'étude des représentations sociales (pp. 59-80). Ramonville Saint-Agne: Éditions Érès.

Alves-Mazzotti, A. J. (2005). Representações sociais e educação: A qualidade da pesquisa como meta política. In D. C. Oliveira \& P. H. F. Campos (Orgs.), Representações sociais, uma teoria sem fronteiras (pp. 141-150). Rio de Janeiro: Museu da República.

Bardin, L. (1992). Análise de conteúdo. Lisboa, Portugal: Edições 70.

Bartlett, F. C. (1995). Remembering: A study in experimental and social psychology. Cambridge: Cambridge University Press. (Original publicado em 1932)

Bassanezi, C. (2004). Mulheres dos anos dourados. In M. Del Priore (Org.), História das mulheres no Brasil (pp. 607-639). São Paulo: Contexto.

Bosi, E. (1994). Memória e sociedade: Lembranças de velhos. São Paulo: Companhia das Letras.

Bosi, E. (2003). O tempo vivo da memória: Ensaios de psicologia social. São Paulo: Ateliê editorial.

Brasil. Ministério da Educação. Secretaria Especial dos Direitos humanos. (2005). Estatuto da Criança e do Adolescente. Brasília: MEC.

Buarque, C. (1993). O que é apartação: $O$ apartheid social no Brasil. São Paulo: Brasiliense.

Cipriani, R. (1988). Biografia e cultura: Da religião à política. In O. M. Simson (Org.), Experimentos com histórias de vida: Itália-Brasil (pp. 107121). São Paulo: Vertíce.

Conway, M. A. (1990). Associations between autobiographical memories and concepts. Journal of Experimental Psychology: Learning, Memory, and Cognition, 16, 799-812.

Conway, M. A. (1991). In defense of everyday memory. American Psychologist, 46, 19-26. 
Conway, M. A. (1995). Autobiographical knowledge and autobiographical memories. In D. C. Rubin (Org.), Remembering our past: Studies in autobiographical memory (pp. 67-93). Cambridge, UK: Cambridge University Press

Conway, M. A. (1998). El inventario de la experiencia: Memoria e identidad. In D. Paez, J. F. Valencia, J. W. Pennebaker, B. Rime, \& D. Jodelet (Orgs.), Memorias colectivas de processos culturales y políticos (pp. 49-82). Bilbao: Universidad del País Vasco.

Cruz, F. M. L. (2006). Representações sociais, identidade e exclusão social: $\mathrm{O}$ fracasso escolar em matemática. In A. Almeida, M. F. S. Santos, G. R. S. Diniz, \& Z. A. Trindade (Orgs.), Violência, exclusão social e desenvolvimento humano: Estudos em representações sociais (pp. 151-186). Brasília: EdUnB.

De Rosa, A. S., \& Mormino, C. (2000). Memoria social, identidad nacional y representaciones sociales: ¿Son constructos convergentes? Un estudio sobre la Union Europea y sus Estados miembros com una mirada hacia el pasado. In A. Rosa, G. Bellelli \& D. Bakhurst (Orgs.), Memoria colectiva e identidad nacional (pp. 451-475). Madrid: Biblioteca Nueva.

Emelyanova, T. (2002). Les représentations sociales des événements historiques: Le cas de la Deuxième Guerre mondiale. In S. Laurens \& N. Roussiau (Orgs.), La mémoire sociale: Identités et représentations sociales (pp.139-150). Rennes: Presses Universitaires de Rennes.

Esteban, M. T. (2001). O que sabe quem erra? Reflexões sobre avaliação e fracasso escolar. Rio de Janeiro: DP\&A.

Freire, P (1992). Pedagogia da autonomia: Saberes necessários a prática educativa. São Paulo: Paz e Terra.

Freitas, L. C. (2002). A internalização da exclusão. Educação e Sociedade, 23(80), 299-325.

Gadotti, M. (1998). Projeto político-pedagógico da escola cidadã. In Salto para o futuro: Construindo a escola cidadã. Brasília: Ministério da Educação e Desporto.
Gilly, M. (2001). As representações sociais no campo da educação. In D. Jodelet (Org.), As representações sociais (pp.321-342). Rio de Janeiro: Eduerj.

Góes de Oliveira, J. L. (1997). Exclusão social: Questões conceituais e doutrinárias. O Social em Questão, 2(2), 15-28.

Halbwachs, M. (1994). Les cadres sociaux de la mémoire. Paris: Édition Albin Michel. (Original publicado em 1925)

Halbwachs, M. (2006). A memória coletiva. São Paulo: Vértice.

Instituto Brasileiro de Geografia e Estatística (IBGE). (2000). Censo demográfico 2000. Brasília: IBGE.

Instituto Nacional de Estudos e Pesquisas Educacionais Anísio Teixeira (INEP). (2006). Sinopse estatística da educação básica 2006. Recuperado em 12 outubro 2007, de http:// www.inep.gov.br/basica/censo/Escolar/Sinopse/ sinopse.asp

Jedlowski, P. (1997). Colletive memories: Theoretical, methodological and practical issues. In SmallGroup Meeting on Collective Memory (pp. 2330). Bari: European Association of Experimental Social Psychology, Università di Bari e Università di Roma "La Sapienza".

Jedlowski, P. (2001). Memory and Sociology: Themes and issues. Time \& Society, 10, 29-44.

Jodelet, D. (1999) Pensée et mémoire sociale. In D. Jodelet (Org.), Manuel de psychologie sociale (pp.111-159). Paris: J. P. Petard Ed.

Joutard, P. (2000). História oral: Balanço e da produção nos últimos 25 anos. In M. M. Ferreira \& J. Amado (Orgs.), Usos e abusos da história oral (pp. 45-61). Rio de Janeiro: Editora FGV

Laurens, S. (2002). La nostalgie dans l'élaboration des souvenirs. In S. Laurens \& N. Roussiau (Orgs.), La mémoire sociale: Identités et représentations sociales (pp.259-268). Rennes: Presses Universitaires de Rennes.

Manacorda, M. A. (2006). História da educação: Da antiguidade aos nossos dias. São Paulo: Cortez. 
Naiff,L.A.M., Sá, C.P. \& Naiff, D.G.M. (2008). Memória e representações sociais da educação 137

Martins, J. S. (1997). Exclusão Social e a nova desigualdade. São Paulo: Paulus.

Meihy, J. C. S. B. (1996). Manual de história oral. São Paulo: Loyola.

Middleton, D., \& Edwards, D. (1990). Collective remembering. London: Sage.

Mucchielli, L., \& Pluet-Despatin, G. (2001). Halbwachs no collège de France. Revista Brasileira de História, 21(40), 13-23.

Namer, G. (1987). Mémoire et société. Paris: Méridiens Klincksieck.

Nascimento, E. P. (2000). Dos excluídos necessários aos excluídos desnecessários. In M. Bursztyn (Org.), No meio da rua (pp.56-87). Rio de Janeiro: Garamond.

Nacimento, A., \& Menandro, P. (2006). Análise lexical e análise de conteúdo: Uma proposta de utilização conjugada. Estudos e Pesquisas em Psicologia, 6(2), 72- 88.

Naiff, L. A. M. (2005). De mãe para filha, o legado da exclusão social: Um estudo das memórias autobiográficas. Tese de doutorado nãopublicada, Universidade do Estado do Rio de Janeiro, Rio de janeiro.

Naiff, L. A. M., \& Naiff, D. G. M. (2007). Representações sociais no contexto escolar: Os desafios da escolarização de jovens e adultos no município do Rio de Janeiro [CD- ROM]. In Anais da Jornada Internacional, 5. Brasília: Universidade de Brasília.

Páez, D., Basabe, N., \& González, J. L. (1998). Memoria colectiva y traumas políticos: Investigación transcultural de los processos sociales del recuerdo de sucesos políticos traumáticos. In D. Paez, J. F. Valencia, J. W. Pennebaker, B. Rime, \& D. Jodelet (Eds.), Memorias colectivas de processos culturales y políticos (pp. 171-206). Bilbao: Universidad del País Vasco,

Patto, M. H. S. (1999). O Mito do fracasso escolar. São Paulo: Casa do Psicólogo.
Paugam, S. (1999). O enfraquecimento e a ruptura dos vínculos sociais: Uma dimensão essencial do processo de desqualificação social. In B. Sawaia (Org.), As artimanhas da exclusão (pp. 67-86). Petrópolis: Vozes.

Perrenoud, P. (2004). Os ciclos da aprendizagem: Um caminho para combater o fracasso escolar. Porto Alegre: Artmed.

Prefeitura do Rio de Janeiro. (2001). Moradia, segregação, desigualdade e sustentabilidade urbana. Rio Estudos, 31. Recuperado em 20 novembro 2004, de http://www.armazemdosdados.rj.gov.br

Rocha-Coutinho, M. L. (1994). Tecendo por trás dos panos: A mulher brasileira nas relações familiares. Rio de Janeiro: Rocco.

Rosa, A., Bellelli, G., \& Bakhurst, D. (2000). Representaciones del pasado, cultura personal e identidad nacional. In A. Rosa, G. Bellelli, \& D. Bakhurst (Orgs.), Memoria colectiva $e$ identidad nacional (pp. 41-90). Madrid: Biblioteca Nueva.

Roussiau, N., Bonardi, C. (2002). Quelle place occupe la mémoire sociale dans le champ des reprèsentations sociales? In S. Laurens \& N. Rousiau (Orgs.), La mémoire sociale: Identités et représentations sociales ( p. 33-49). Rennes: Presses Universitaires de Rennes

Sá, C. P. (2005). As memórias da memória social. In C. P. Sá (Org.), Memória, imaginário e representações sociais (pp.63-83). Rio de Janeiro: Editora Museu da República.

Sá, C. P. (2007). Sobre o campo de estudos da memória social: Uma perspectiva psicossocial. Psicologia: Reflexão e Crítica, 20, 290-295.

Sá, C. P., Möller, R. C., \& Medeiros, A. A. (1990). Contracontrole social na educação: Repre-sentações sociais da escola pública em uma favela do Rio de Janeiro. Fórum educacional, 14(3), 93-108.

Saviani, D. (2006). As concepções pedagógicas na história da educação brasileira. In J Lombradi, D. Saviani \& M. I. M. Nascimento (Orgs.), Navegando na história da educação Brasileira (pp. 60-75). Campinas: HISTEDBR. 
Schwartz, B. (1990). The reconstruction of Abraham Lincoln. In D. Middleton \& D. Edwards (Orgs.), Collective remembering (pp. 81-107). London: Sage.

Senna, M. C. M., Burlandy, L., Monnerat, G. L., Schottz, V., \& Magalhães, R. (2007). Programa bolsa família: Nova institucionalidade no campo da política social brasileira? Revista Katálises, 10, 86-94.

Singer, P. (1998). Globalização e desemprego: Diagnóstico e alternativas. São Paulo: Contexto.

Szymanski, H. (2006). Práticas educativas familiares e o sentido da constituição identitária [Versão eletrônica]. Paidéia (Ribeirão Preto), 16. Recuperado em 29 maio 2008, de http:// www.scielo.br/paideia

Van Der Veer, R. (2001). Remembering bartlett. Culture \& Psychology, 7(2), 223-229.

Véras, M. (1999). Exclusão Social: Um problema brasileiro de 500 anos. In B. Sawaia (Org.), As artimanhas da exclusão (pp. 27-52). Petrópolis: Vozes

Viaud, J. (2002). Contribution à l'actualisation de la mémoire collective. In S. Laurens \& N. Roussiau (Orgs.), La mémoire sociale: Identités et représentations sociales (pp.21-32). Rennes: Presses Universitaires de Rennes.

Vieira, S. L,. \& Farias, I. M. S. (2007). Política educacional no Brasil. Brasília: Liber Livro.

Artigo recebido em 13/07/2007.

Aceito para publicação em 29/04/2008.

Endereço para correspondência:

Luciene Alves Miguez Naiff. Rua Conselheiro Olegario, 34 apt 103, Maracanã. CEP 20271-090. Rio de Janeiro-RJ, Brasil.E-mail: lunaiff@hotmail.com

Luciene Alves Miguez Naiff é Professor Titular da Universidade Salgado de Oliveira.
Celso Pereira de Sá é Professor Titular do Instituto de Psicologia da Universidade do Estado do Rio de Janeiro.

Denis Giovani Monteiro Naiff é Professor Adjunto do Instituto de Educação da Universidade Federal Rural do Rio de Janeiro. 